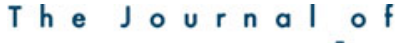 \\ Laryngology \& Otology}

cambridge.org/jlo

\section{Litigation in otology, and diagnosis and treatment delay; prognosis of olfactory disorders in coronavirus disease 2019; and ENT redeployment in the pandemic}

\author{
Edward W Fisher and Jonathan Fishman, Senior Editors
}

\section{Editorial}

Cite this article: Fisher EW, Fishman J. Litigation in otology, and diagnosis and treatment delay; prognosis of olfactory disorders in coronavirus disease 2019; and ENT redeployment in the pandemic. $J$ Laryngol Otol 2021;135:377-378. https://doi.org/ $10.1017 /$ S0022215121001316
Litigation in otolaryngology in England was the subject of a recent article in Clinical Otolaryngology by the 'Getting it Right First Time' ('GRIFT') group. ' The same group have contributed a sister article to this issue of The Journal of Laryngology \& Otology, which focuses on litigation in otology, ${ }^{2}$ updating the messages in an article in The Journal by Metcalfe and colleagues a few years ago. ${ }^{3}$ The most expensive claims were from stapedectomy (average of over $£ 750$ 000; maximum total cost of over $£ 4$ million), and the main reasons for claims were: delay in or failure of treatment, delay in or failure of diagnosis, intra-operative complications, and inadequate consent. Given the Montgomery versus Lanarkshire case, which has been much discussed (but not always translated into proper change in process), the rise in consent-related litigation is hardly surprising, but combating this risk is in the hands of individual clinicians. Metcalfe and colleagues' study showed that consent problems accounted for around 9 per cent of cases, and 57 per cent of claims were successful. The corresponding proportion in the more recent paper is 13 per cent of cases. The authors note that 'On an individual level, auditing and reflecting on a surgeon's consent process could act as a straightforward method for reducing the risk of litigation'. Delays in diagnosis and treatment are perhaps more of a concern, accounting for the biggest category of litigation, as the coronavirus disease 2019 (Covid-19) pandemic has inevitably caused a great spike in delays which is outside of the control of individual clinicians.

The flow of articles on Covid-19 related matters continues, and this issue of The Journal revisits the matter of the natural history of smell and taste disorders during and after Covid-19 infection. ${ }^{4,5}$ Petrocelli and colleagues from Bologna, Italy, ${ }^{4}$ examined smell and taste in in-patients with severe acute respiratory distress syndrome, testing during the acute illness period (first 7 days), and then at one, two, three and six months. This paper compliments their previous articles, ${ }^{6,7}$ which explain their methods and give initial results. The authors found that at six months, 27 per cent of 300 subjects had persistent olfactory disturbance and 1 per cent had anosmia. The corresponding figures for taste were 10 per cent and 1 per cent respectively, with the improvement from baseline reaching a plateau at one month. Seventy per cent of patients had some chemosensory symptoms during the infection. A paper from Tehran, Iran, by Jalessi and colleagues, ${ }^{5}$ deals with a different group of patients, those who reported smell disturbance but had mild Covid-19 symptoms, rhinological symptoms or no accompanying symptoms at all (and so were 'probable' Covid-19 cases, not confirmed by polymerase chain reaction). The patients were followed up by telephone interview. In this study, 71 per cent of patients recovered completely within 5.5 months, and the presence of other nasal symptoms was associated with prolonged olfactory disturbance. Favourable prognostic factors were young age and gastrointestinal symptoms.

A thoughtful 'qualitative' study from London, UK, is included this month, which examines a small number of ENT trainees and investigates their feelings about redeployment during the Covid-19 pandemic. ${ }^{8}$ This study should help in the planning of redeployment should future similar situations arise. Many aspects of the psychological effects are discussed, as well as the trainees' feelings about their skill sets not being fully utilised. The camaraderie experienced in the new teams is noteworthy, but: '... this team spirit and senior support did not stop the interviewed trainees reporting a high emotional toll from the experience, mirroring that described by other groups of redeployed surgeons'. The need to use an otolaryngologist's unique skill set in redeployment is a theme that resonates with other commentaries, as in a paper by Shipchandler and colleagues from the USA last year. ${ }^{9}$

\section{References}

1 Navarananam AV, Hariri A, Ho C, Machin JT, Briggs TWR, Marshall A. Otorhinolaryngology litigation in England: 727 clinical negligence cases against the NHS. Clin Otolaryngol 2021;46:9-15 
2 McClenaghan F, Ho C, Machin JT, Briggs TWR, Marshall A, Navaratnam $\mathrm{AV}$. What can be learned from litigation in otology? A review of clinical negligence claims in England 2013-2018. J Laryngol Otol 2021;135:379-84

3 Metcalfe CW, Muzaffar SJ, Coulson CJ. Litigation trends and costs in otorhinolaryngology. J Laryngol Otol 2015;129:941-4

4 Petrocelli M, Cutrupi S, Salzano G, Maglitto F, Salzano FA, Lechien JR et al. Six-month smell and taste recovery rates in coronavirus disease 2019 patients: a prospective psychophysical study. J Laryngol Otol 2021;135: 436-41

5 Jalessi M, Bagheri SH, Azad Z, Firouzabadi FD, Amini E, Alizadeh R et al. The outcome of olfactory impairment in patients with otherwise paucisymptomatic coronavirus disease 2019 during the pandemic. J Laryngol Otol 2021;135:426-35
6 Petrocelli M, Ruggiero F, Baietti AM, Pandolfi P, Salzano G, Salzano FA et al. Remote psychophysical evaluation of olfactory and gustatory functions in early-stage coronavirus disease 2019 patients: the Bologna experience of 300 cases. J Laryngol Otol 2020;134:571-6

7 Vaira LA, Hopkins C, Petrocelli M, Lechien JR, Chiesa-Estomba CM, Salzano $\mathrm{G}$ et al. Smell and taste recovery in coronavirus disease 2019 patients: a 60-day objective and prospective study. J Laryngol Otol 2020;134:703-9

8 Lion P, McClenahan F, Hall A, Mackinnon S, Navaratnam AV. ENT trainees' experience of redeployment during the coronavirus disease 2019 pandemic: a qualitative study. J Laryngol Otol 2021;135:391-5

9 Shipchandler TZ, Nesemeier BR, Schmalbach CE, Tin JY. Otolaryngologists' role in redeployment during the COVID-19 pandemic: a commentary. Otolaryngol Head Neck Surg 2020;163:94-5 